\title{
Liderazgo en la educación Una pedagogía para el siglo XXI
}

Belisario Betancur Cuartas *

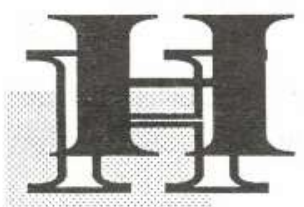

ánfora

\section{Introducción: el indócil corazón}

ace algo más de treinta años, una gélida tarde de noviembre de 1960, en el Aula Máxima de la adusta Universidad se congregaban el pensamiento, la industria, el estudiantado, el ejército, la banca y la iglesia, a rendir homenaje al maestro de maestros. El discurso académico fue asignado, por unanimidad paradojal, a un estudiante de quien, con razón, se esperaba antes una diatriba que un elogio. «Desde hace largos años se trabó un entente cordial entre el maestro severo y cierto estudiante insurrecto decía el orador- que se obstinaba en meterse en sus sueños como en plaza fuerte. Expulsado del claustro, agregaba el insurrecto, llevó por muchos caminos su planta andariega y su indócil corazón errabundo. Trataba de cumplir su propio horóscopo, y antes de aceptar las viejas tablas se refugiaba en la utopía, con vasto gesto mesiánico. No podía expresar con claridad su mensaje, pero lo afirmaba intuitivamente como un presentimiento auroral». Enseguida entró el expositor en disquisiciones académicas profundas, sobre laeducación y las metodologías para irrigar en el alma juvenil y para sembrar en ella. «La escuela, decía, tiene una misión normativa, no simplemente formativa. No puede limitarse a alojar en la mente ajena, como si fuera una bodega, una serie de conocimientos superpuestos y datos eruditos. Poco vale cargar al hombre de fardos intelectuales, si ese saber no se absorbe hasta consubstanciarse con el sujeto, dándole una disciplina interior y sirviéndole como vía de comunicación con el mundo. Al proceso orgánico de humanización, concluía, se le llama cultura».

Aquella tarde fue de excelsitud en el aula máxima de la Universidád de Caldas en Manizales, en honor del maestro don Francisco Marulanda Correa. El discurso del otrora díscolo estudiante, lo decía, tartamudeando pero con acento tribunicio y además arrogante, Gilberto Alzate Avendaño, quien explicaba sus antiguas gestas subversivas, diciendo de sí que «como ocurre con las naturalezas demasiado cargadas de alma, el muchacho -él
«Todo es una sola $\cos a »$

Heráclito (Siglo V AC)

* Intervención del Dr. Belisario Betancur Cuartas con motivo de laConstitición Legal del Instituto CAaldense para el Liderazgo, realizado en el Auditorio de la Cámara de Comercio de Manizales, el 5 de Septiembre de 1994. 
mismo advierto yo-, sufría las peripecias de un drama espiritual y era víctima de la desesperación del conocimiento».

Aquel tema de entonces, el conocimiento, sigue teniendo vigencia ahora: esta tarde nos detendremos a cavilar sobre cómo dirigirse hacia ese saber desinteresado; nos reunimos a reflexionar en torno a cómo construir sobre el conocimiento, las fundaciones del mundo nuevo, en tiempos en que el ser humano revisa todo el saber anterior. Y, en ese mundo nuevo, cómo levantar los cimientos de la Colombia que queremos edificar sobre la base de la educación, para poner nuestro país al alcance de los niños, a fin de que ellos lo transformen y engrandezcan.

\section{Un país para los niños}

En una bella y densa pieza literaria, prólogo para el informe de la Misión de Ciencia, Educación y Desarrollo, entregado al final del gobierno del Presidente César Gaviria en julio de 1994, Gabriel García Márquez discurrió de manera magistral sobre la índole de los colombianos. Cada uno de los elementos de su discurso va en directo al fondo de nuestra identidad como nación; y muchos de ellos, aún fuera de contexto, sirven para construir más de un prolegómeno a los desarrollos que vendrán como consecuencia de las luces arrojadas por el severo diagnóstico. Me inclino hacia uno de los enunciados que, -por insistir en la situación presente-, encarna al tiempo la esencia del desafío planteado por la ampliación del conocimiento para nuestra sociedad global. Lamento y reto irresistible son estas palabras de nuestro Premio Nobel: «Aún estamos lejos de imaginar cuánto dependemos del vasto mundo que ignoramos», y al mirar con lente crítico hacia su contorno, surgen para él, hipótesis de causalidad que racionalmente no se podrían menospreciar. «Nuestra educación conformista y represiva -agrega-, parece concebida para que los niños se adapten por la fuerza a un país que no fue pensado para ellos, en lugar de poner el pais al alcance de ellos para que lo transformen y engrandezcan».

\section{Los arcanos del conocimiento}

Sería ingenuo desconocer la verdad que se encierra en esta afirmación. Sin embargo, cuando descendemos al mundo real, -que es el de una categoría planetaria que nos cobija a todos-, se descubre con rapidez que el procedimiento a que se enfrenta la humanidad, no es diferente al que señala el gran escritor. A este respecto, en un reciente foro realizado por «Le Monde» de París con varios de los más destacados pensadores de este fin de siglo,

* «Les Grands Entretiens du Monde. Penser la Philosophie: Penser les sciences, Penser les Religions».tome 2.Pag. 104.
Thomas Ferenczi sintetizó así el contenido de las reflexiones fascinantes que surgieron de tal convocatoria: «La duda ha sucedido a las certidumbres y las vicisitudes de la investigación al facilismo dogmático»*. Tal conclusión es una forma clara de definir las nuevas teorías sobre el orden y el caos, en la infinita vastedad del cosmos. Lo cual no debe ser motivo de alarma para 
nosotros, ciudadanos del mundo, que apenas presentimos los arcanos del conocimiento pero que nos esforzamos por aproximarnos a una conciencia racional sobre el complejo, que es el denominador común de todo lo real. Hace más de 300 años, Pascal, uno de los grandes pensadores de todos los tiempos, lo había dicho en un escueto aforismo: «todo está en todo y recíprocamente». Y en ese mismo contexto de interrelaciones, el desarrollo del conocimiento nos ha traído al punto neurálgico en que el ser contemporáneo penetra en un nuevo campo de la racionalidad, donde lo impensable es la mejor medida de lo probable como también de lo posible.

No es fácil ubicarse en esta nueva dimensión antropológica. En otras situaciones comparables, los seres humanos se hundieron en el nihilismo y en la desesperanza. No porque se les hubieran cerrado los caminos, sino porque fueron incapaces de construir una nueva racionalidad sin ataduras determinadas y sin superticiones. Edgar Morin, una estrella viva del pensamiento, afirma que, «todas las ideologías que han prometido la certidumbre -de la revolución de la sociedad industrial al afán del desarrollo, han fallado". Lo cual, observa, no debe implicar el paso de la certidumbre irracional a la incertidumbre radical. La evolución del pensamiento y la realidad de la interdependencia global, obligan a repensarlo todo. A abrir el paso hacia la elaboración de una «nueva sintaxis» en la afortunada expresión de Jean Desanti y, -por qué no decirlo-, a un estado de alma en que la «esperanza trágica», -como figura que trata de construir el ciclo del caos al orden-, conduzca al fin a la construcción de los cimientos para una «nueva razón ética y colectiva», como la concibe serenamente el Cardenal Josef Ratzinger.

El mundo se lo están disputando siempre, Dios y el diablo. Por lo que se ve en Bosnia y en Ruanda, va ganando el diablo. Siempre el conflicto, la violencia y la guerra como telón de fondo que disimula a los vendedores de armas. Los cuales es sabido que pertenecen a las mejores familias, y son tenaces y persuasivos hasta conseguir que Madagascar, que no tiene conflictos, mantenga un ejército bien armado de 20 mil soldados. Las referencias geográficas remotas, se explican porque todo está en todo, todo está en conexión con todo. Tanto, que en un encuentro mundial de pensamiento a comienzos de 1994, en Segovia, España, le oí decir a la socióloga Margaret Stacey, que un monje budista se sentía atormentado al saber que una joven de doce años se suicidó después de haber sido violada. «Llámenme por mis nombres verdaderos, gemía el monje budista; yo soy la niña violada; yo soy el violador. Todos somos el todo".

\section{Pensar y repensar el país}

Puedo adivinar, y aún percibir, algún grado de perplejidad aflorando ya en este auditorio preparado mentalmente para discurrir sobre el conocimiento, como lo hicieron el maestro Marulanda Correa y sus discípulos, Aquilino y 
Silvio Villegas, el Padre Fabo, Danilo Cruz Vélez y José Vélez Sáenz, entre otros. Sin embargo, la osadía intelectual y el estímulo de esta audiencia, me llevan a ir más allá de referencias, -acaso necesarias y siempre pertinentes, a los esquemas formales de la temática educativa. Sea este el momento de recordar a otro apóstol desaparecido esta semana: Reinaldo Arroyave Lopera, quien fue ejemplo de empresarios y de educadores, que no conoció el descanso, ni tuvo límites en su búsqueda de los más altos valores del espíritu, para impulsar programas innovadores en la educación.

La vida enseña que, por definición, los programas de gobierno están inspirados en la buena intención, mucho más cuando sus objetivos básicos se refieren a las generaciones que harán el futuro de la nación. No obstante, la historia también enseña que la naturaleza humana cae en las visiones restringidas y en las apreciaciones fragmentadas de la realidad social. Tengamos presente, además, el hecho de que la humanidad se está viendo enfrentada a un número infinito de cambios impensados. Una razón más a

Como lo expresaría García

Márquez, nuestros niños deben no sólo penetrar a un país pensado para ellos, sino entrar en ese país para repensarlo continuamente, en función de sus raíces planetarias y en la trayectoria de sus ensoñaciones. fin de reconocer que el gran prerrequisito para la educación reside en la estructura de una «conciencia de época y de interdependencia», más que en esquemas curriculares sin conexión con una realidad sistémica. Como lo expresaría García Márquez, nuestros niños deben no sólo penetrar a un país pensado para ellos, sino entrar en ese país a sabiendas de que su compromiso primero está en adquirir una disciplina para repensar ese mismo país continuamente, en función de sus raíces planetarias y en la trayectoria de sus ensoñaciones.

Es una empresa colosal. Porque el parroquialismo de la mente humana impidió aceptar que, no obstante la humilde confesión socrática del «solo sé que nada sé», la soberbia de los poderes que administraron el mundo, siguió comportándose como si la tierra fuera el centro del universo y como si sus recursos tuvieran carácter inagotable. Y, en más de una ocasión, como si lo supieran todo, como siningún conocimiento escapara a su inteligencia, esos poderes siguieron actuando con ceguera. Menos mal que en la voluble condición humana persistió siempre un sentido de supervivencia; una condición inspirada por la inmanencia de valores humanísticos yacentes en todas las culturas intuídas o creadas y protagonizadas por el ser humano.

\section{Aun estamos en la prehistoria}

En esa conciencia ecuménica debe reposar la tarea de la educación. Sin embargo, para ello no basta que, en apariencia, pueda decirse que los niños de hoy y los que abrirán sus ojos con el advenimiento del nuevo milenio, estén o vayan a estar predispuestos para conectarse con el vasto territorio de una sociedad global. Deberíamos decir que existen tantas barreras como diferencias abismales, entre los componentes de esa gran comunidad planetaria. No sólo en cuanto a niveles individuales de conocimiento, de oportunidades y de bienestar, sino también en cuanto a las percepciones de 
la especie humana sobre la realidad del cosmos. La «ignorancia sobre todo» está expresada en el hecho de que, según el consenso de la ciencia mundial, a duras penas conocemos el $10 \%$ de la materia y poco o nada sabemos todavía sobre el origen de la vida. Lo cual no representa una mala noticia para el futuro humano: es la mayor fuente de su incertudimbre (en el sentido nuevo de esta palabra), pero también el generador de más retos para la creatividad del ser humano. Por tanto, no debe asombrarnos la afirmación de Edgar Morin, que adivino en la misma línea de Theilard de Chardin, el gran profeta del siglo XX, de que, desde el punto de vista de la era planetaria, «aún estamos en la prehistoria del espíritu humano y en la edad de hierro de la civilización» que ambos describen con lucidez comparable, en términos de historia representa un fenómeno «reciente». Aunque, -bueno es repetirlo-, es el ser humano mismo quien tiene en sus manos la posibilidad de jugar racionalmente con lo incierto y complejo a fin de construir del mejor modo el futuro para su planeta GAIA, que bien poco o nada significa en la infinitud del cosmos. Pero que lo significa todo para la especie humanidad.

No se está jugando, pues, con fútiles lucubraciones cuando se habla de incorporar en el proceso educativo la creación de conciencia sobre esta virtualidad de la condición humana. Que requiere, nuevas formas de racionalización en el marco de una estructura antropológica renovada. Un estadio al que no será posible llegar sin haber construído previamente los puentes hacia nuevas formas de rectoría, que es la hermosa tarea acometida por el Instituto FES de Liderazgo, y al que ahora se suma con clara visión anticipatoria el Instituto Caldense de Liderazgo. Todo ello en la perspectiva de diseñar una pedagogía para la globalidad, desde el punto de vista de los valores éticos y de la plenitud de sus derechos, que sirva de muro de contención a la hecatombe moral que se adivina.

\section{EI hombre nuevo}

Acceder a estas esferas requiere la creación de un ser nuevo. Y aunque el especimen humano a finales del siglo XX está plagado de contradicciones, resulta posible que de ellas surjan las respuestas que abran los espacios requeridos para la renovación. La multipersonalidad del alma hace que el ser humano históricamente no haya dejado de ser ángel y demonio al mismo tiempo, como antes dije. No obstante, un signo de la virtualidad que esa condición intrínseca entraña, puede estar en las nuevas aproximaciones entre la ciencia y la filosofía, cuyos caminos no han sido siempre paralelos.

La historia de la civilización occidental está marcada por esas distanciás no exentas de contradicciones. Hasta el punto de que, por momentos, ciencia y filosofía en algunas de sus vertientes, parecieron divorciarse. Uno de tales momentos lo marcó el siglo de las luces, que enfrentó su tiranía de la razón a la tradición de las verdades reveladas. Sin embargo, tarde o temprano la reconciliación entre filosofía y ciencia tenía que resultar un imperativo 
racional. Lo más estimulante para quienes, como profanos miramos con realista perplejidad tales contradicciones, es que fueron los propios avances centíficos y sus locuras destructivas, los que produjeron ese afanoso reencuentro. «Científico por vocación, he llegado a la filosofía en razón de los interrogantes que el acontecimiento de Hiroshima plantea para las generaciones que vienen», confesó humilde y sabiamente Michel Serres, uno de las lumbreras del pensamiento filosófico y científico de nuestra época, que visitó en 1993 a Cartagena de Indias con la misión de veinte sabios reunida por la Unesco. La cual también recomendó un cambio en las metodologías consuetudinarias de la educación y, concretamente, la universidad a distancia.

\section{Sin rueda y sin yunta}

Como colombianos, latinoamericanos, estamos situados en un punto del planeta donde se expresa con más intensidad el milagro de la vida y de la concatenación del mayor número de millones de organismos vivos existentes, ni siquiera clasificados por los hombres de ciencia. Esta debería ser una de las mayores razones para no permanecer indiferentes frente a una realidad tan espléndida como lastimosamente ignorada. Ser habitantes del trópico húmedo significa estar en el centro biológico terrestre. Algo que poco nos inspiró y poco nos inspira para decir a nuestros educandos. Muy al contrario, casi que tradicionalmente fomentó en nosotros un síndrome vergonzante y digno de ocultarse. Que posiblemente tenga que ver con nuestro distanciamiento de los desarrollos del conocimiento, perotambién con un desarrollode cortepuramente académico y elitista, de la ciencia y de la tecnología encasilladas en disciplinas curriculares que nunca se intentó siquiera relacionar. Por fortuna, las nuevas corrientes del pensamiento se han venido aproximandoa un manejodemocrático de los grandes temas de la ciencia y del conocimiento aplicado. A ello ha contribuido la transformación inimaginada en el mundo de la informática y de los medios audiovisuales. Ellos han permitido que, -siendo conscientes de que para el común de la gente y aún para una buena parte de la propia comunidad científica, resulta inalcanzablelaplena comprensión de las interrelacionesentre todo y todo-, sí es posible, al menos, crear una conciencia racional de que ellas existen.

«Contextualizar» es no sólo una nueva expresión del vocabulario científico actual -que debe empezar a figurar en nuestro repertorio lexicográfico de uso diario-, sino también una disciplina inculcada desde la infancia, que, podría o debería llegar a ser casi instintiva. Como lo fue posiblemente la sabiduría arcaica y oral, que aniquiló o quiso aniquilar la cultura escrita, pero a la cual se empieza a hacer justicia desde las más altas cimas del conocimiento científico. Rastros asombrosos de esa sabiduría prehistóri-

* Tales of a Shaman's Apprentice» Viking Press, 1994 ca, quedan aún en las culturas precolombianas: Mark Plotkin, uno de los sabios de nuestro tiempo, enamorado de nuestra selva húmeda, ha revelado en su últimơ libro* lo que va quedando de esa despensa. 
Pero de paso reafirma hechos dignos de recordar. Uno de esos hechos es que buena parte de las especies vegetales que dan origen a la actual cosecha alimentaria mundial, fue descubierta y domesticada sin rueda y sin yunta, por los agricultores precolombinos. Casi las mismas especies, incluído el maíz, originario de la selva húmeda mexicana, hacen hoy de Estados Unidos la primera potencia agrícola mundial. En el caso del maíz, basta con transcribir lo que dicen Edgar Morin y Anne Brigitte Kern en un libro que titularon «TERRE -PATRIE»*: «Los modos de preparación del maíz en el México precolombino, fueron regularmente atribuidos por los antropólogos a ciencias mágicas, hasta que se ha descubierto que a través de esos sistemas de cultivo, se permitía que el organismo humano asimilar a lisina, sustancia nutritiva de lo que fue, por muy largo tiempo, la base casi única de alimentación para los aztecas. Así que lo que parecía «irracional» correspondía a una «racionalidad vital». Por algo, añadiría yo, se ha dicho que la magia fue la primera forma de ciencia aplicada.

\section{Una pedagogía de la globalidad}

No es vana pretensión querer abrirse paso con razones, en contradicción con muchas de las realidades que abruman a los seres humanos. Racionalizar la interdependencia de la complejidad, en el mundo atomizado que dejó la guerra fría, parece una empresa imposible. Mucho más cuando las escalas de valores opuestos que, desde su perspectiva quiso imponer cada uno de los bandos enfrentados, han quedado cuestionadas. Lo cual representa el mejor punto de partida para construir una pedagogía preventiva, que evite al ser humano caer de nuevo en la trampa de los ideologismos estrechos y alienantes.

El peligro fundamentalista no está asociado tan sólo con la exacerbación de los irracionalismos religiosos y étnicos. También puede ir encerrado en los despliegues idolátricos frente al mercado, o en el maniqueísmo de algunas posturas neoliberales o neonacionalistas. Dentro del nuevo pensamiento antropológico que supone la planetización de la vida humana, es posible que terminemos aceptando que el epicentro del fundamentalismo no está en las esencias del islamismo, sino en la desfiguración de éste o de cualquier otro credo político o religioso. Por qué habríamos de relacionar necesariamente al Islam con una naturaleza diabólica y anárquica, cuando nosotros, -iberoamericanos como prolongación del mestizaje hispano-árabe-judio-, traemos en nuestra sangre los rasgos genéticos que inspiraron la sabiduría monumental de Maimónides, de Averroes, Al-Razi y Avizeni, los primeros en tratar de conciliar el pensamiento judío e islámico con la propia visión aristotélicacristiana, prolongada con la obra de Tomás de Aquino? Entender el mestizaje cultural y científico en el marco de nuestra sociedad planetaria, es evitar que los verdaderos fundamentalismos terminen arrasando nuestra capacidad racional para hallar ocultas interrelaciones entre los más evidentes contrarios: entre muerte y resurección, entre enfermedad y ansia de vida. ¿No podría ser ese un buen comienzo para una pedagogía ecuménica?
* EditionsDuSeuil.Paris, 1993.

...construir una pedagogía preventiva, que evite al ser humano caer de nuevo en la trampa de los ideologismos estrechos y alienantes. 


\section{Una nueva antropología}

...desencadenar un cataclismo del saber desinteresasacudimiento de la razón práctica.
El alma colombiana tiene potencialidades demostradas para emprender ese vuelo. Leamos y releamos la evocación de Maestro García Márquez, que puede ser vista como un provocativo juicio autocrítico desde las raíces nacionales: es la misma visión implícita en las nuevas corrientes del pensamiento contemporáneo, que debe convertirse en un ejercicio diario, en la conciencia de cada ciudadano del mundo, en el centro de cada comunidad ideal o de cada una de las partes que integran la «aldea global».

Estas reflexiones -inducidas desde Atenas por el gran colombiano que es el embajador Mario Calderón Rivera-, he querido formularlas ante un auditorio analítico como el de Manizales, para suscitar una controversia cuyo resplandor ilumine el trayecto actual de la vida colombiana; que es tanto como decir que lo que quiero es desencadenar un cataclismo del saber desinteresado, un sacudimiento de la razón práctica. La razón por encima de la emoción, dirá que desde nuestro escenario particular, podemos provocar impulsos de alcance global, con el simple reordenamiento de nuestras virtualidades contrarias.

A estas alturas quedarán pocos que duden sobre el alcance de la vacuna sintética concebida y realizada por nuestro eminente compatriota Manuel Elkin Patarroyo. Porque, sin apelar a recursos hiperbólicos, porque en la perspectiva del futuro humano ese avance del conocimiento aplicado tiene más significación que el gesto desesperado y a veces teatral del nuevo intervencionismo humanitario, por bien inspirado que pueda parecer. Pero que no va ni puede ir más allá de una siniestra punta de iceberg, que es apenas el comienzo de afloración de un tercio de la población terrestre, arrasada por las delirantes contradicciones de un modelo de desarrollo que ignoró la ley inexorable de las interdependencias.

Tenemos tiempo para recomenzar. «Un pueblo -escribía Aquilino Villegasnecesita una meta que brille en el horizonte como la cimera de Palas; querer alcanzarla con voluntad indomable; y gastar en la empresa la totalidad de sus esfuerzos». Si, tenemos tiempo para recomenzar. En nuestra propia conciencia, en la intimidad familiar, en las aulas escolares, en la universidad, en la agenda comunitaria, el futuro comenzará cuando sintamos que todos dependemos de todos. Es posible que ese día seamos conscientes de que hemos reencontrado el camino hacia una nueva antropología, que quizá podamos llamar verdaderamente cristiana. 